\title{
Facile Solvothermal Synthesis of BiOCl/ZnO Heterostructures with Enhanced Photocatalytic Activity
}

\author{
Yong-Fang Li, ${ }^{1}$ Ming Zhang, ${ }^{2}$ Dan-Lu Guo, ${ }^{3}$ Fei-Xia He, ${ }^{3}$ Ying-Zhu Li, ${ }^{3}$ and Ai-Jun Wang ${ }^{3}$ \\ ${ }^{1}$ College of Chemistry and Chemical Engineering, Henan Institute of Science and Technology, Xinxiang 453003, China \\ ${ }^{2}$ School of Chemistry and Chemical Engineering, Henan Normal University, Xinxiang 453007, China \\ ${ }^{3}$ College of Geography and Environmental Science, Zhejiang Normal University, Jinhua 321000, China \\ Correspondence should be addressed to Ai-Jun Wang; ajwang@zjnu.cn
}

Received 3 October 2014; Accepted 7 December 2014; Published 18 December 2014

Academic Editor: Gong-Ru Lin

Copyright (C) 2014 Yong-Fang Li et al. This is an open access article distributed under the Creative Commons Attribution License, which permits unrestricted use, distribution, and reproduction in any medium, provided the original work is properly cited.

Well-defined nanosheet-assembled $(\mathrm{BiOCl})_{x}(\mathrm{ZnO})_{1-x}$ nanoflowers were synthesized by a solvothermal method. It was found that $\mathrm{ZnO}$ nanoparticles were anchored on the flower-like $\mathrm{BiOCl}$ nanostructures, as demonstrated by varying the initial compositions of the $\mathrm{Bi}$ precursor and the volume ratios of mixed solvents (ethylene glycol to water). The as-prepared $(\mathrm{BiOCl})_{0.6}(\mathrm{ZnO})_{0.4}$ nanocomposites showed enhanced photocatalytic activity toward rhodamine B degradation under ultraviolet (UV) irradiation. And the photocatalytic mechanism was discussed in detail.

\section{Introduction}

Zinc oxide $(\mathrm{ZnO})$ has broad applications in transparent electronics, solar cells, piezoelectric devices, chemical sensors, spin electronics, and optical devices, owing to its excellent electrical, biocompatible, optical, and chemical properties [1-6]. However, only ultraviolet light $(\lambda<385 \mathrm{~nm})$ can be utilized for pure $\mathrm{ZnO}$, because of its wide band gap energy $(3.37 \mathrm{eV})$ that severely hinders its practical applications [1, $2,7,8]$. Furthermore, the fast recombination rate of photogenerated electron-hole pairs is another critical drawback in photocatalytic reactions. Therefore, it is still a challenge to extend its photoresponses and improve the separation efficiency of electron-hole pairs.

To date, one effective approach is to modify $\mathrm{ZnO}$ surface with a narrow and proper band gap semiconductor, because the built-in potential gradient at the interface promotes the separation of electron-hole pairs and reduces the chance of recombination, resulting in the improved photocatalytic efficiency as compared to pure $\mathrm{ZnO}$ counterparts $[9,10]$. Therefore, a series of hybrid nanomaterials were prepared, on the basis of $\mathrm{ZnO}$ coupled with many metals (e.g., $\mathrm{Ce}, \mathrm{Al}$, $\mathrm{Cr}, \mathrm{Ag}$, and $\mathrm{Zr}$ ) [11-14], metal oxides (e.g., $\mathrm{TiO}_{2}, \mathrm{SnO}_{2}$, and $\mathrm{Bi}_{2} \mathrm{O}_{3}$ ) [15-18], and metal sulfides (e.g., $\mathrm{Cu}_{2} \mathrm{~S}$ and $\mathrm{CdS}$ ) [1921].
Recently, bismuth oxyhalides ( $\mathrm{BiOX}, \mathrm{X}=\mathrm{Cl}, \mathrm{Br}$, and I) display unique optical properties such as the improved photocatalytic activity on the degradation of organic contaminant [15] and industrial applications [22-24], compared with single counterparts. Zhang and coworkers synthesized $\mathrm{BiOI} / \mathrm{TiO}_{2}$ heterostructures at low temperature [15]. Lately, $\mathrm{BiOCl}$ with heterostructures as a kind of new photocatalyst has attracted great attention [25-28]. For example, Cheng's groups prepared $\mathrm{Bi}_{2} \mathrm{~S}_{3}$ nanocrystals/ $\mathrm{BiOCl}$ nanocomposites under solvothermal conditions [25]. Weng et al. constructed $\mathrm{Bi} / \mathrm{BiOCl}$ hybrid nanosheets by a UV light-induced chemical reduction route [26].

In this work, a facile solvothermal method was developed to prepare monodisperse nanosheet-assembled nanoflowers of $(\mathrm{BiOCl})_{x}(\mathrm{ZnO})_{1-x}$. Their photocatalytic activity was investigated through the degradation of rhodamine $B(\mathrm{RhB})$ under ultraviolet (UV) irradiation. And the possible photocatalytic mechanism was discussed in some detail.

\section{Experimental Section}

2.1. Chemicals and Materials. Ethylene glycol (EG), $\mathrm{Zn}(\mathrm{Ac})_{2}$. $2 \mathrm{H}_{2} \mathrm{O}, \mathrm{Bi}\left(\mathrm{NO}_{3}\right)_{3} \cdot 5 \mathrm{H}_{2} \mathrm{O}$, and rhodamine $\mathrm{B}$ were purchased from Shanghai Chemical Reagent Corporation. All the other chemicals were of analytical grade and used as received. 


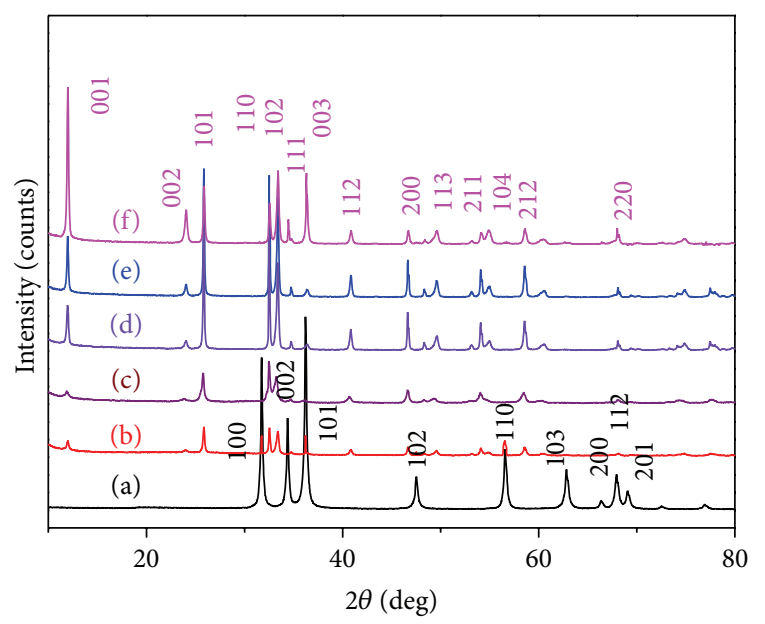

FIgURE 1: XRD patterns of the $(\mathrm{BiOCl})_{x}(\mathrm{ZnO})_{1-x}$ powders: $\mathrm{ZnO}$ (curve (a)), $(\mathrm{BiOCl})_{0.4}(\mathrm{ZnO})_{0.6}(\operatorname{curve}(\mathrm{b})),(\mathrm{BiOCl})_{0.6}(\mathrm{ZnO})_{0.4}$ (curve $(\mathrm{c})),(\mathrm{BiOCl})_{0.7}(\mathrm{ZnO})_{0.3}($ curve $(\mathrm{d})),(\mathrm{BiOCl})_{0.75}(\mathrm{ZnO})_{0.25}$ (curve (e)), and $\mathrm{BiOCl}$ (curve (f)).

All the aqueous solutions were prepared with twice-distilled water throughout the whole experiments.

2.2. Preparation. For preparation of $(\mathrm{BiOCl})_{x}(\mathrm{ZnO})_{1-x}$ heterostructures, different amounts of $\mathrm{Bi}\left(\mathrm{NO}_{3}\right)_{3} \cdot 5 \mathrm{H}_{2} \mathrm{O}$ were slowly put into $15 \mathrm{~mL}$ of EG solution containing $0.01 \mathrm{~mol}$ of $\mathrm{Zn}(\mathrm{Ac})_{2}$ under stirring for $1 \mathrm{~h}$, followed by dropwise addition of $5 \mathrm{~mL}$ of water. Next, $5 \mathrm{~mL}$ of $\mathrm{KCl}$ solution with the same content of $\mathrm{Bi}\left(\mathrm{NO}_{3}\right)_{3}$ was put into the mixed solution and continuously stirred for $1 \mathrm{~h}$. The resulting mixture was transferred into $50 \mathrm{~mL}$ Teflon-lined stainless steel autoclave, sealed tightly, heated at $120^{\circ} \mathrm{C}$ for $12 \mathrm{~h}$, and then cooled to room temperature naturally. Finally, the products were collected by thoroughly washing with water and ethanol and dried in vacuum at $50^{\circ} \mathrm{C}$. The $\mathrm{BiOCl}$ contents (wt $\%$ ) were $0 \%, 40 \%, 60 \%, 70 \%, 75 \%$, and $100 \%$, denoted by $\mathrm{ZnO},(\mathrm{BiOCl})_{0.4}(\mathrm{ZnO})_{0.6},(\mathrm{BiOCl})_{0.6}(\mathrm{ZnO})_{0.4}$, $(\mathrm{BiOCl})_{0.7}(\mathrm{ZnO})_{0.3},(\mathrm{BiOCl})_{0.75}(\mathrm{ZnO})_{0.25}$, and $\mathrm{BiOCl}$ of the final products, respectively.

For comparison, pure $\mathrm{BiOCl}$ and $\mathrm{ZnO}$ were mechanically mixed (denoted by $\left.(\mathrm{BiOCl})_{x}+(\mathrm{ZnO})_{1-x}\right)$ to evaluate the role of heterojunctions on the photocatalytic activity of the $\mathrm{BiOCl} / \mathrm{ZnO}$ samples.

2.3. Characterization. The crystal structures of the samples were characterized by X-ray diffraction (XRD) on a BrukerD8-AXS diffractometer system equipped with a $\mathrm{Cu} \mathrm{K} \alpha$ source. The morphology and particle size were analyzed by a scanning electron microscope (SEM, JEOL-JSM-6390 LV). Transmission electron microscopy (TEM) and highresolution TEM (HRTEM) images were obtained with a JEOL JEM-2100F system at $200 \mathrm{kV}$ accelerating voltage. A small amount of the sample was prepared by dispersing the final products in ethanol by ultrasonication and then a drop of the solution was deposited on a $\mathrm{Cu}$ grid for TEM observation. $\mathrm{UV}$-vis diffuse reflectance spectra (DRS) were analyzed by a PerkinElmer Lambda $950 \mathrm{UV}$-vis spectrometer and $\mathrm{BaSO}_{4}$ was used as a reference. X-ray photoelectron spectra (XPS) were recorded by using a K-Alpha (K $\alpha$ ) XPS spectrometer (ThermoFisher, E. Grinstead, UK) with an Al K $\alpha$ X-ray radiation $(1486.6 \mathrm{eV})$ for excitation. The contaminant carbon $\left(\mathrm{C}_{1 \mathrm{~S}}=284.6 \mathrm{eV}\right)$ was used as a standard to calibrate all binding energies.

2.4. Photocatalytic Measurements. The photocatalytic ability of the samples was examined by photocatalytic decolorization of RhB in aqueous solution using UV irradiation at ambient temperature. A 300 W Hg lamp (Yaming Company, Shanghai, $8 \mathrm{~cm}$ away from the suspension) was used as a light source to trigger the photocatalytic reaction. Typically, $0.06 \mathrm{~g}$ of the sample was put into a $60 \mathrm{~mL}$ of the RhB solution $\left(40 \mathrm{mg} \mathrm{L}^{-1}\right)$ in a reaction cell with a Pyrex jacket. Before irradiation with UV, the suspension was stirred for $1 \mathrm{~h}$ in dark to reach an adsorption-desorption equilibrium. After irradiation for different time intervals, the samples were taken out from the reaction system, centrifuged at $12000 \mathrm{rpm}$ for $10 \mathrm{~min}$ to remove the photocatalyst, followed by measuring the corresponding UV-vis spectra. All the experiments were conducted at room temperature.

\section{Results and Discussion}

3.1. Characterization of the $\mathrm{BiOCl} / \mathrm{ZnO}$ Heterostructures. Solvothermal synthesis is a robust method for preparing heterostructures such as alloys and homogeneous compositions that display practical applications in catalytic field and thereby is an advantageous way to tune the properties of a catalyst [4]. X-ray diffraction (XRD) patterns of the $(\mathrm{BiOCl})_{x}(\mathrm{ZnO})_{1-x}$ heterostructures (Figure 1) exhibit typical diffraction peaks corresponding to the wurtzite structured $\mathrm{ZnO}$ (JCPDS card number 36-1451) and/or the tetragonal phase BiOCl (JCPDS card number 06-0249), respectively. The sharp peaks reveal a high degree of crystallization for the products. Furthermore, with the increase of the $\mathrm{BiOCl}$ content (wt $\%$ ) up to $100 \%$, the peaks from $\mathrm{BiOCl}$ are gradually increased, while the peaks from $\mathrm{ZnO}$ phase are almost unchanged as the $\mathrm{BiOCl}$ content (wt\%) is at or above $60 \%$ (Figure 1, curve c-f). It means crystal growth inhibition of $\mathrm{ZnO}$ for the existence of $\mathrm{BiOCl}$. Additionally, no other crystalline impurities are detected, further confirming high purity of the products.

The surface chemical compositions and oxidation states of the $(\mathrm{BiOCl})_{x}(\mathrm{ZnO})_{1-x}$ heterostructures were further investigated by X-ray photoelectron spectroscopy (XPS). Taking the surface of the $(\mathrm{BiOCl})_{0.6}(\mathrm{ZnO})_{0.4}$ sample as an example (see Figure S1 in Supplementary Material available online at http://dx.doi.org/10.1155/2014/347061), Zn, O, Bi, $\mathrm{Cl}$, and a trace amount of $\mathrm{C}$ elements coexist based on the XPS survey spectrum. Moreover, as revealed by highresolution XPS spectra (Figure 2), the peaks located at 1021.5 and $1044.7 \mathrm{eV}$ are assigned to the binding energy of $\mathrm{Zn}_{2 \mathrm{p} 3 / 2}$ and $\mathrm{Zn}_{2 \mathrm{p} 1 / 2}$, respectively (Figure $2(\mathrm{a})$ ), which are in good agreement with those in $\mathrm{ZnO}$ structures [7]. The peaks emerged at 159.0 and $164.3 \mathrm{eV}$ are attributed to the binding energy of $\mathrm{Bi}_{4 \mathrm{f} 7 / 2}$ and $\mathrm{Bi}_{4 \mathrm{f5} / 2}$, respectively (Figure $2(\mathrm{~b})$ ), which 


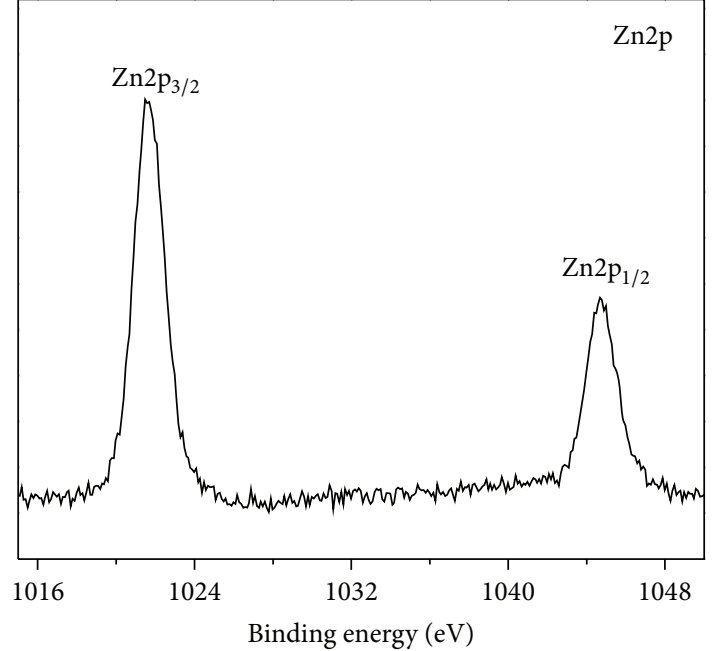

(a)

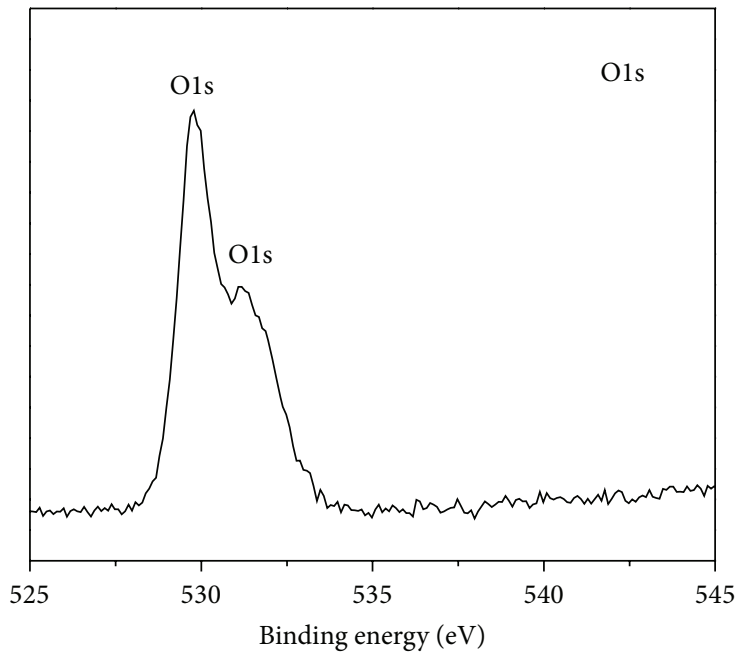

(c)

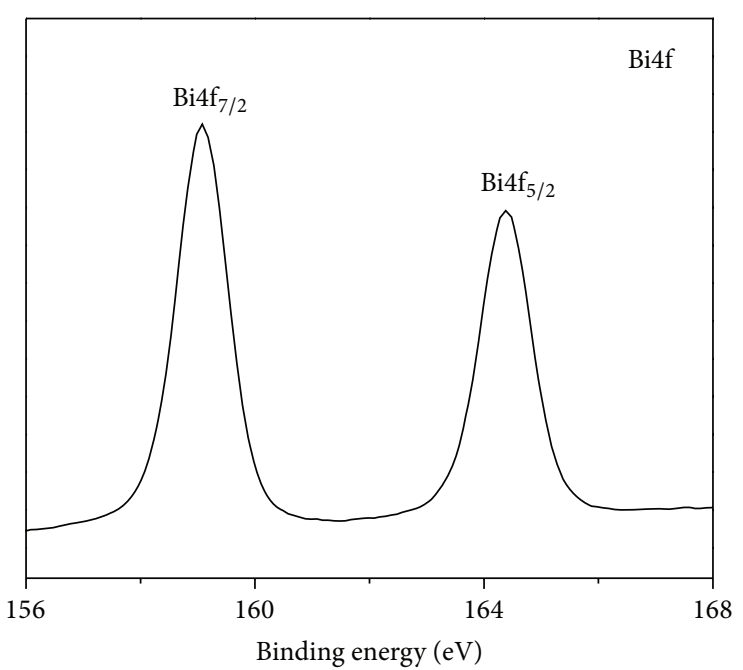

(b)

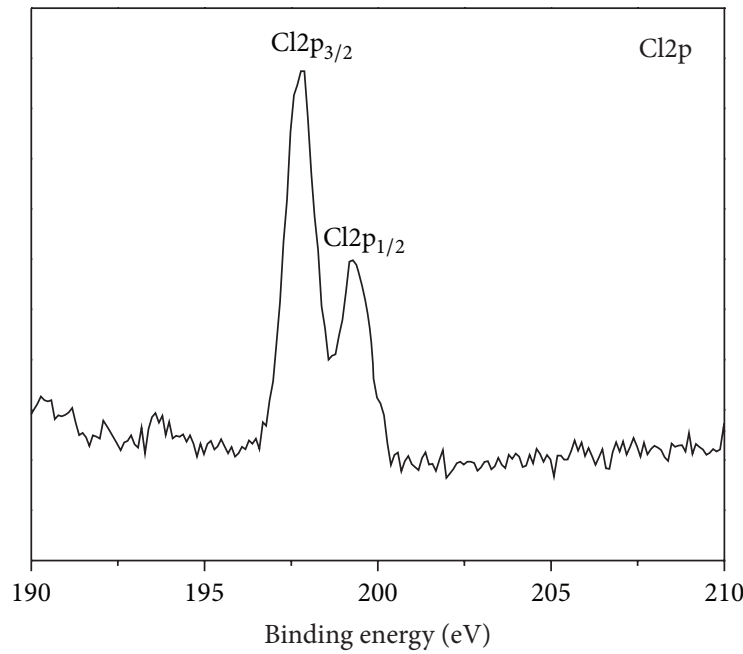

(d)

FIgURE 2: High-resolution XPS spectra of the $\left(\mathrm{BiOCl}_{0.6}(\mathrm{ZnO})_{0.4}\right.$ powders: $\mathrm{Zn}_{2 \mathrm{p}}(\mathrm{a}), \mathrm{Bi}_{4 \mathrm{f}}(\mathrm{b}), \mathrm{O}_{1 \mathrm{~s}}(\mathrm{c})$, and $\mathrm{Cl}_{2 \mathrm{p}}(\mathrm{d})$.

are associated with $\mathrm{Bi}^{3+}$ and $\mathrm{Bi}^{4+}[15,29]$, respectively. Meanwhile, the satellite peaks appeared near the peaks of $\mathrm{Bi}_{4 \mathrm{f} 7 / 2}$ and $\mathrm{Bi}_{455 / 2}$ with a distance of $1.8 \mathrm{eV}$, which is similar to that in the previous literature [15]. And an asymmetric peak of $\mathrm{O}_{1 \mathrm{~s}}$ is detected (Figure 2(c)), indicating the presence of two oxygen species in the adjacent regions. The peak at $531.1 \mathrm{eV}$ corresponds to the $\mathrm{Zn}-\mathrm{O}$ bonds [7], whereas the peak at $529.1 \mathrm{eV}$ is attributed to the $\mathrm{Bi}-\mathrm{O}$ bond in $\mathrm{Bi}_{2} \mathrm{O}_{2}$ slabs of $\mathrm{BiOCl}$ layered structures [15]. In addition, the peaks at 197.7 $\left(\mathrm{Cl}_{2 \mathrm{p} 3 / 2}\right)$ and $199.2\left(\mathrm{Cl}_{2 \mathrm{p} 1 / 2}\right) \mathrm{eV}$ are ascribed to pure $\mathrm{BiOCl}$ in the XPS spectrum of the $\mathrm{Cl}_{2 \mathrm{p}}$ core level (Figure 2(d)). The above XRD and XPS analysis confirm the coexistence of $\mathrm{BiOCl}$ and $\mathrm{ZnO}$ in the $(\mathrm{BiOCl})_{x}(\mathrm{ZnO})_{1-x}$ heterostructures, while either $\mathrm{Bi}$ or $\mathrm{Cl}$ species is not incorporated into $\mathrm{ZnO}$ lattice because of low temperature, as supported by the XRD data.

The physiochemical property of one solvent is essential to its solubility, reactivity, and diffusion behaviors, along with its intermediates [30]. In this system, the growth of $(\mathrm{BiOCl})_{0.6}(\mathrm{ZnO})_{0.4}$ heterostructures strongly depends on the mixed solvents of EG and water by varying their volume ratios (Figure 3), while other conditions are kept the same. Using EG as a single solvent yields numerous interconnected nanosheet-assembled spheres with the average diameter of $2 \mu \mathrm{m}$ (Figure 3(a)). When the volume ratio of EG to water is 23:2 (Figure 3(b)), similar spheres are obtained, while their size is enlarged to $10 \mu \mathrm{m}$. These microspheres are assembled by a lot of nanoplates aligned radically and tightly with several nanometers in thickness, as revealed by higher magnification SEM image (inset in Figure 3(b)). Interestingly, by reducing the ratio to $21: 4$, some microspheres are transformed to sheet-like nanostructures (Figure 3(c)). Flower-like structures are dominated with the ratio of 18:7 (Figure 3(d)), in which each flower contains four petals assembled by nanosheets. Decreasing the ratio to $15: 10$ produces many well-defined microflowers with smaller diameter of $4-5 \mu \mathrm{m}$ 


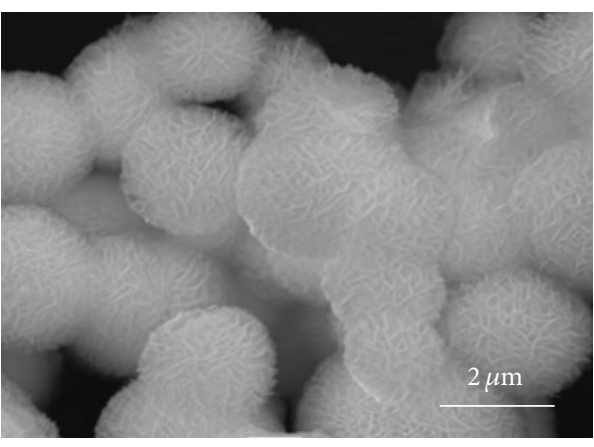

(a)

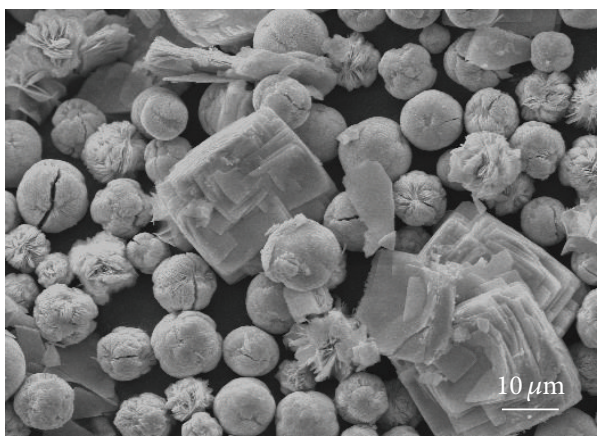

(c)

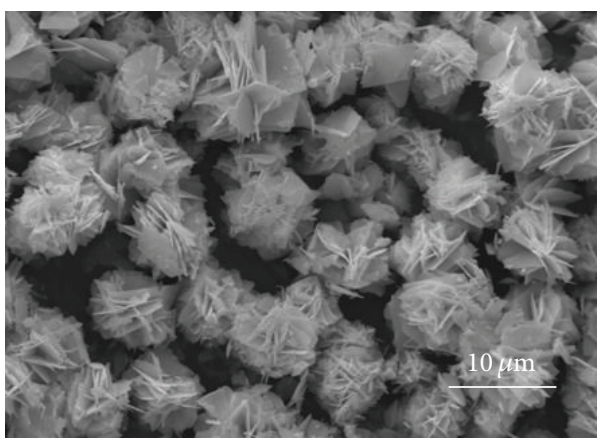

(e)

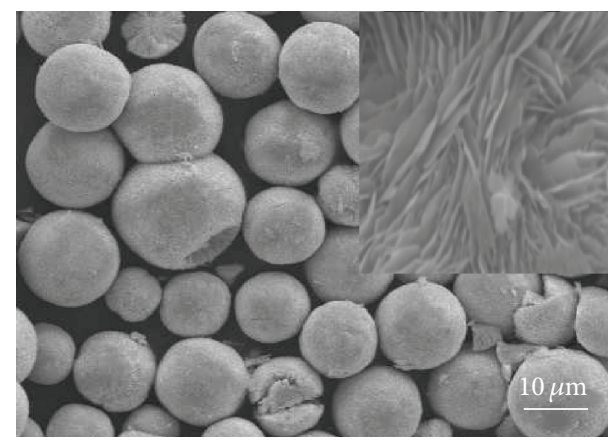

(b)

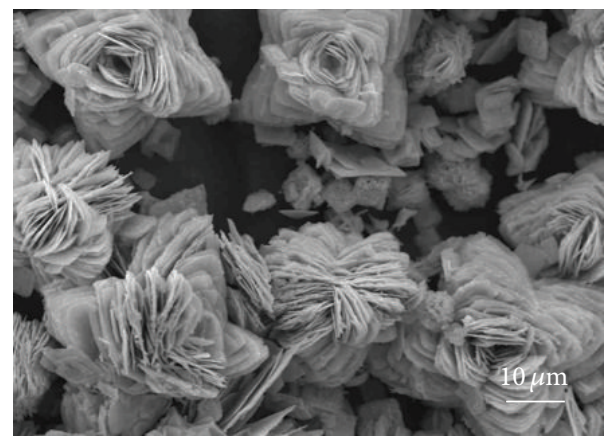

(d)

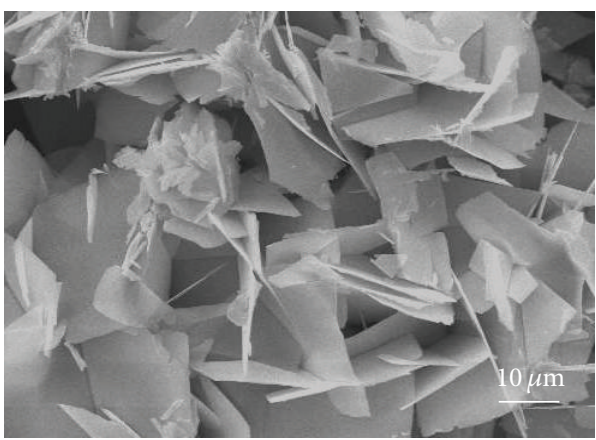

(f)

FIGURE 3: SEM images of the $(\mathrm{BiOCl})_{0.6}(\mathrm{ZnO})_{0.4}$ composites prepared by different volume ratios of EG to water: (a) $25: 0$, (b) $23: 2$, (c) $21: 4$, (d) $18: 7$, (e) $15: 10$, and (f) $0: 25$.

(Figure 3(e)). However, a large number of nanoplates are obtained only using water as a solvent (Figure 3(f)).

In our work, water is an amphiprotic solvent, where most inorganic salts are readily dissolved. In contrast, EG possesses strong chelation, which can coordinate with free $\mathrm{Bi}^{3+}$ and $\mathrm{Zn}^{2+}$ to form alkoxides, leading to the decrease of the growth rate of $\mathrm{BiOCl}$ and $\mathrm{ZnO}$. This is ascribed to the fact that EG molecules can exist in long chains where hydrogen bonds are formed between hydroxyl groups [23]. Herein, EG acts as a soft template and directs the growth of heterogeneous nanoparticles into nanoplates at the very early stage, followed by the EG-induced self-assembly of unstable microspheres, eventually resulting in well-defined microspheres via a dissolution-recrystallization process, as demonstrated by the SEM experiments (Figure 3).

Furthermore, the amount of the $\mathrm{Bi}$ precursor is also important for the $(\mathrm{BiOCl})_{x}(\mathrm{ZnO})_{1-x}$ heterostructures
(Figure 4), while other conditions remain constant. The absence of the $\mathrm{Bi}$ precursor yields plenty of $\mathrm{ZnO}$ flowers assembled by many smooth nanoplates, with the average diameter of 3-6 $\mu \mathrm{m}$ (Figure S2A, Supporting Information). In the presence of $40 \% \mathrm{BiOCl}$, the products contain a series of flower-like spheres with the mean diameter size of $4 \mu \mathrm{m}$, which are built by many nanopetals connected together from the centre to form flower-like structures (Figure 4(a)). Similar structures are obtained by increasing the supply of $\mathrm{BiOCl}$ up to $75 \%$ (Figures 4(c)-4(d)). However, the only presence of the Bi precursor produces uniform apple-like $\mathrm{BiOCl}$ hierarchical structures with the average diameter of $3 \mu \mathrm{m}$ (Figure S2B, Supporting Information). These results indicate that the $\mathrm{Bi}$ precursor is critical to the formation of the $(\mathrm{BiOCl})_{x}(\mathrm{ZnO})_{1-x}$ nanocomposites.

A more detailed insight of the $(\mathrm{BiOCl})_{0.6}(\mathrm{ZnO})_{0.4}$ heterostructures was examined by TEM and HRTEM 


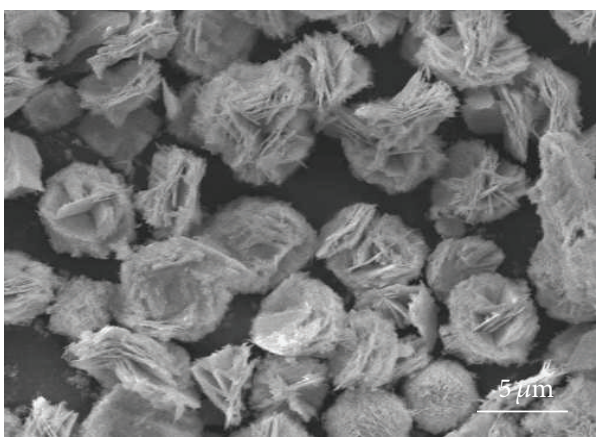

(a)

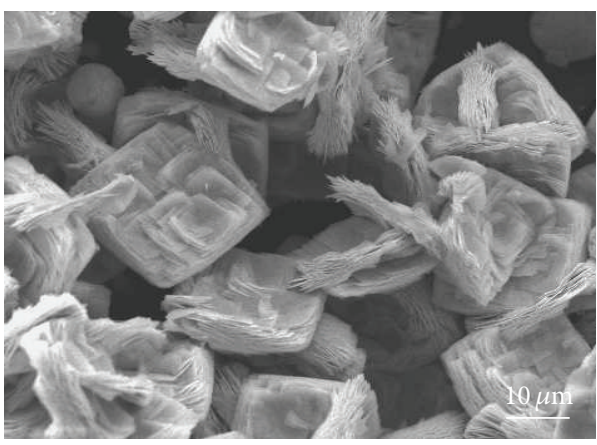

(c)

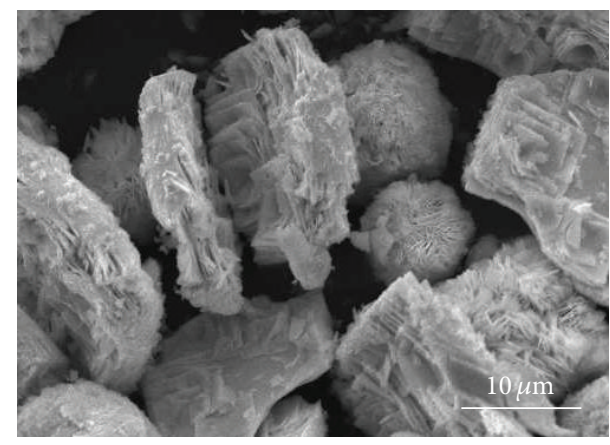

(b)

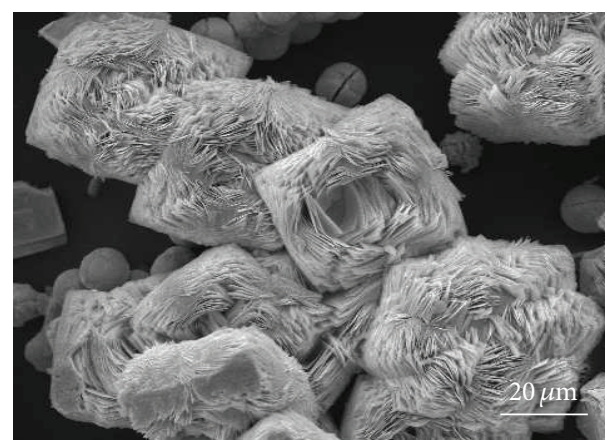

(d)

FIGURE 4: SEM images of the $(\mathrm{BiOCl})_{x}(\mathrm{ZnO})_{1-x}$ composites: $(\mathrm{BiOCl})_{0.4}(\mathrm{ZnO})_{0.6}(\mathrm{a}),(\mathrm{BiOCl})_{0.6}(\mathrm{ZnO})_{0.4}(\mathrm{~b}),(\mathrm{BiOCl})_{0.7}(\mathrm{ZnO})_{0.3}(\mathrm{c})$, and $(\mathrm{BiOCl})_{0.75}(\mathrm{ZnO})_{0.25}(\mathrm{~d})$.

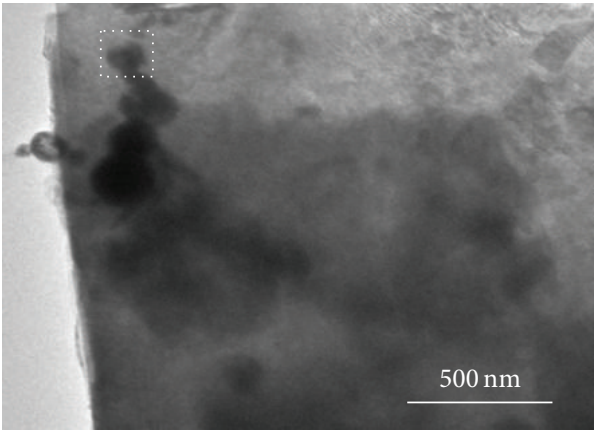

(a)

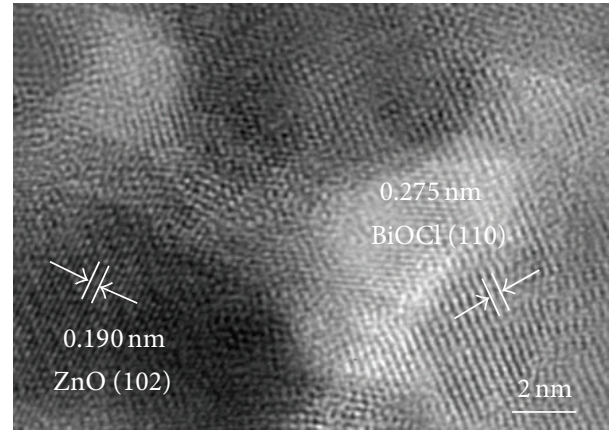

(b)

Figure 5: TEM (a) and HRTEM (b) images of the $(\mathrm{BiOCl})_{0.6}(\mathrm{ZnO})_{0.4}$ composites.

measurements after dispersion of the sample under ultrasonication (Figure 5). Some nanoparticles are still attached but not peeled off from the sheet-like subunits (Figure 5(a)), indicating the strong interactions between the $\mathrm{ZnO}$ nanoparticles and the sheets. The as-prepared composites are highly crystallized, as confirmed by the lattice fringes with a $d$-spacing values of $0.275 \mathrm{~nm}$ and $0.190 \mathrm{~nm}$ from the HRTEM measurements (Figure 5(b)), corresponding to the (110) planes of $\mathrm{BiOCl}[26-28]$ and the (102) planes of $\mathrm{ZnO}[31,32]$, respectively, indicating the coexistence of $\mathrm{BiOCl}$ and $\mathrm{ZnO}$ in the present synthesis. The $\mathrm{ZnO}$ nanoparticles exist in the nanosheets subunits of the $\mathrm{BiOCl}$ flowers. Meanwhile, the $\mathrm{ZnO}$ nanoparticles further confirm why the associated $\mathrm{ZnO}$ diffraction peaks are difficult to distinguish when the content of $\mathrm{BiOCl}$ is at or above $60 \%$.
3.2. Optical Properties. The UV-vis diffuse reflectance spectra (DRS) patterns of the $(\mathrm{BiOCl})_{x}(\mathrm{ZnO})_{1-x}$ composites reveal the optical responses are greatly changed in the range of 350-420 nm (Figure 6(a)). Varying the BiOCl content has significant effects on the absorption peak for the samples. This is ascribed to light absorption of $\mathrm{BiOCl}$ nanoparticles on the $\mathrm{ZnO}$ nanosheet. The band gap energy $\left(E_{g}\right)$ of a semiconductor would be estimated from the following equation:

$$
\alpha h v=A\left(h v-E_{g}\right)^{n / 2}
$$

where $\alpha, \nu, E_{g}$, and $A$ are absorption coefficient, light frequency, band gap energy, and a constant, respectively. For individual $\mathrm{ZnO}$ or $\mathrm{BiOCl}$, the value of $n$ is 4 for the indirect transition. As displayed in Figure 6(b), the $E_{g}$ for 


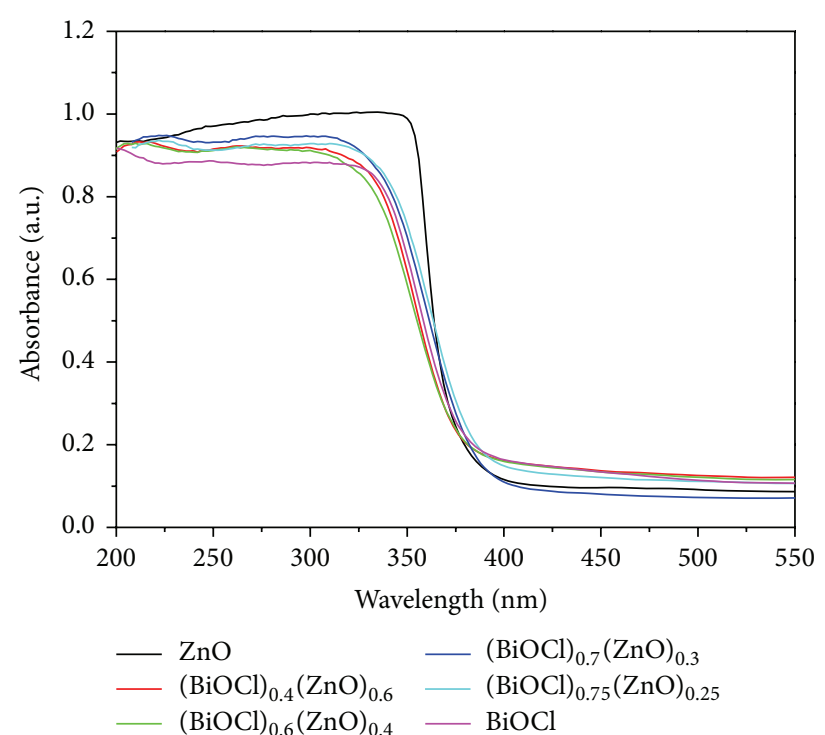

(a)

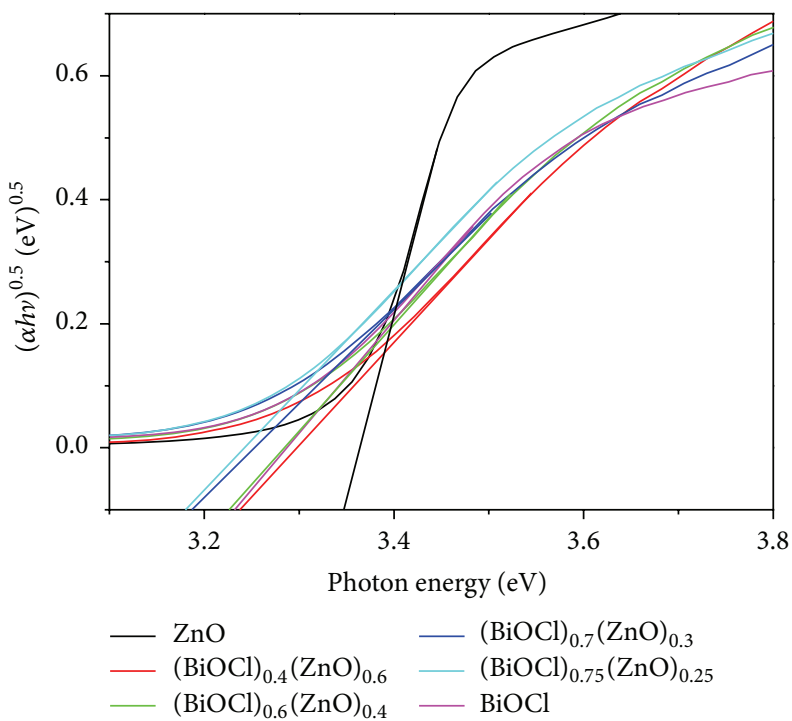

(b)

Figure 6: (a) UV-vis diffuse reflectance spectra of the $(\mathrm{BiOCl})_{x}(\mathrm{ZnO})_{1-x}$ composites. (b) The corresponding plot of $(\alpha h v)^{0.5}$ versus photon energy.

TABLE 1: Band gaps and photocatalytic activities of the $(\mathrm{BiOCl})_{x}(\mathrm{ZnO})_{1-x}$ composites.

\begin{tabular}{lcc}
\hline Samples & Band gap $(\mathrm{eV})$ & $k\left(\mathrm{~min}^{-1}\right)$ \\
\hline $\mathrm{ZnO}$ & 3.35 & 0.00030 \\
$(\mathrm{BiOCl})_{0.4}(\mathrm{ZnO})_{0.6}$ & 3.24 & 0.00539 \\
$(\mathrm{BiOCl})_{0.6}(\mathrm{ZnO})_{0.4}$ & 3.22 & 0.00732 \\
$(\mathrm{BiOCl})_{0.7}(\mathrm{ZnO})_{0.3}$ & 3.19 & 0.00465 \\
$(\mathrm{BiOCl})_{0.75}(\mathrm{ZnO})_{0.25}$ & 3.18 & 0.00241 \\
$\mathrm{BiOCl}$ & 3.23 & 0.00014 \\
$(\mathrm{BiOCl})_{0.6}+(\mathrm{ZnO})_{0.4}$ & - & 0.00214 \\
\hline
\end{tabular}

the $(\mathrm{BiOCl})_{x}(\mathrm{ZnO})_{1-x}$ composites can be determined by the intercept of the tangent to the $x$-axis (Table 1), which is slightly decreased as the content of $\mathrm{BiOCl}$ is increased, accompanied with the slight red shift of the associated absorption peaks (Figure 6(a)), owing to the recombination of $\mathrm{BiOCl}$ and $\mathrm{ZnO}$ in this work.

3.3. Photocatalytic Activity. It is known that the absorption in UV region would increase the number of photogenerated electrons and holes in the photocatalytic reaction [20]. RhB is a kind of chemically stable dye pollutants. Herein, the photolysis of RhB by UV irradiation is significant under our experimental conditions. Thus, the photocatalytic ability of the $(\mathrm{BiOCl})_{x}(\mathrm{ZnO})_{1-x}$ composites was investigated, using the photocatalytic degradation of $\mathrm{RhB}$ by $\mathrm{UV}$ irradiation as a model system. Taking the $(\mathrm{BiOCl})_{0.6}(\mathrm{ZnO})_{0.4}$ composites as an example, a series of UV-vis absorption spectra were recorded in a $60 \mathrm{~mL}$ aqueous solution containing $40 \mathrm{mg} \mathrm{L}^{-1}$ $\mathrm{RhB}$ and $0.06 \mathrm{~g}(\mathrm{BiOCl})_{0.6}(\mathrm{ZnO})_{0.4}$ at different time intervals (Figure 7, curves (a)-(i)). The characteristic absorption peak

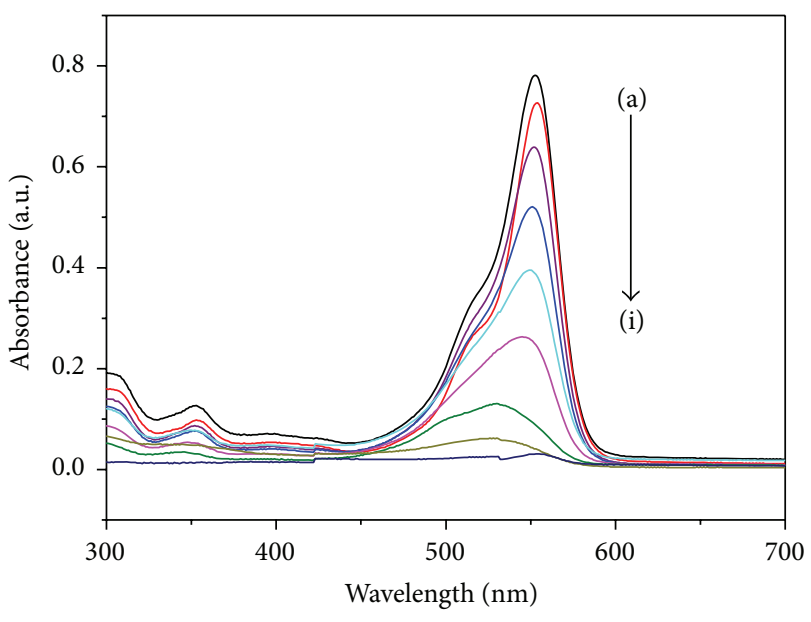

FIGURE 7: UV-vis absorption spectra of the RhB solution $\left(40 \mathrm{mg} \mathrm{L}^{-1}\right)$ containing $1.0 \mathrm{mg} \mathrm{mL}^{-1}(\mathrm{BiOCl})_{0.6}(\mathrm{ZnO})_{0.4}$ composites at different time intervals; (a) to (i) $0 \mathrm{~min}, 10 \mathrm{~min}, 20 \mathrm{~min}, 40 \mathrm{~min}, 60 \mathrm{~min}$, $80 \mathrm{~min}, 100 \mathrm{~min}, 120 \mathrm{~min}$, and $140 \mathrm{~min}$.

of $\mathrm{RhB}$ at $551 \mathrm{~nm}$ quickly decreases by increasing the irradiation time and even disappears when the time is $140 \mathrm{~min}$, indicating complete degradation of $\mathrm{RhB}$ in the system.

During the photocatalytic reaction process, using the mechanically mixed $(\mathrm{BiOCl})_{0.6}+(\mathrm{ZnO})_{0.4}$ instead of the $(\mathrm{BiOCl})_{0.6}(\mathrm{ZnO})_{0.4}$ composites, while other conditions remain constant (Figure 8), the absorption peak of $\mathrm{RhB}$ at $551 \mathrm{~nm}$ is slightly decreased, implying the existence of heterojunctions between $\mathrm{BiOCl}$ and $\mathrm{ZnO}$ in the $(\mathrm{BiOCl})_{0.6}(\mathrm{ZnO})_{0.4}$ composites. This is due to the effective separation of electron-hole pairs from $\mathrm{ZnO}$ by the heterojunctions and the abundant hydroxyl groups 


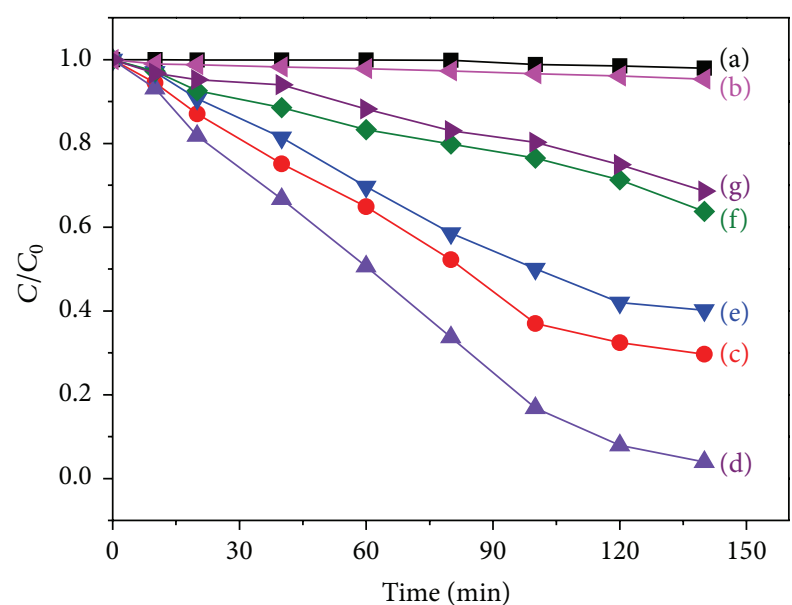

FIgURE 8: Photocatalytic activities of the $(\mathrm{BiOCl})_{x}(\mathrm{ZnO})_{1-x}$ composites ((a) to (f) $\mathrm{ZnO}, \mathrm{BiOCl},(\mathrm{BiOCl})_{0.4}(\mathrm{ZnO})_{0.6},(\mathrm{BiOCl})_{0.6}$ $(\mathrm{ZnO})_{0.4},(\mathrm{BiOCl})_{0.7}(\mathrm{ZnO})_{0.3}$, and $\left.(\mathrm{BiOCl})_{0.75}(\mathrm{ZnO})_{0.25}\right)$ and the mixture of $(\mathrm{BiOCl})_{0.6}+(\mathrm{ZnO})_{0.4}(\mathrm{~g})$ on the degradation of $\mathrm{RhB}$ under UV irradiation.

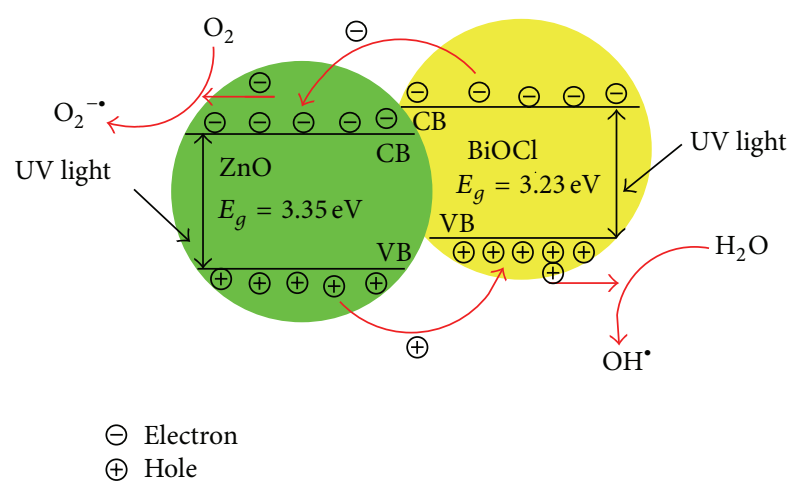

FIGURE 9: Schematic illustration of the electron-transfer process in the $(\mathrm{BiOCl})_{x}(\mathrm{ZnO})_{1-x}$ heterostructures under UV irradiation.

on the samples surface. However, further increasing the content of $\mathrm{BiOCl}$ (e.g., the $(\mathrm{BiOCl})_{0.4}(\mathrm{ZnO})_{0.6}$ and $(\mathrm{BiOCl})_{0.7}(\mathrm{ZnO})_{0.3}$ samples) leads to incomplete degradation of $\mathrm{RhB}$, because excess $\mathrm{BiOCl}$ would cover the surface active sites of $\mathrm{ZnO}$. Interestingly, single $\mathrm{ZnO}$ and $\mathrm{BiOCl}$ in the reaction media would cause negligible $\mathrm{RhB}$ degradation with the value of $4 \%$ and $6 \%$, respectively. It indicates that the coupling of $\mathrm{BiOCl}$ with $\mathrm{ZnO}$ clearly contributed to the degradation of $\mathrm{RhB}$. These results demonstrate the enhanced photocatalytic activity of the $(\mathrm{BiOCl})_{0.6}(\mathrm{ZnO})_{0.4}$ composites among the $(\mathrm{BiOCl})_{x}(\mathrm{ZnO})_{1-x}$ composites.

In addition, the stability of the $(\mathrm{BiOCl})_{0.6}(\mathrm{ZnO})_{0.4} \mathrm{com}$ posites was examined. After repeated use of the catalysts for 5 times, the degradation of RhB still remained above $85 \%$ of their initial values ( $96 \%)$. Meanwhile, for a storage period of 2 months, the RhB degradation is above $90 \%$ of their initial values under the same conditions. These results mean that the $(\mathrm{BiOCl})_{0.6}(\mathrm{ZnO})_{0.4}$ composites can be recycled and stored.
Assuming initial low concentration of the pollutant, the pseudo-first-order model was used to elucidate the reaction kinetics, as expressed by

$$
\ln \left(\frac{C_{0}}{C}\right)=k t,
$$

where $C / C_{0}$ was used to denote the percentage of degradation, $C$ is the concentration of $\mathrm{RhB}$ after degradation and $C_{0}$ is the initial concentration of $\mathrm{RhB}$, and $k$ is the pseudo-first-order rate constant. The rate constant for the $(\mathrm{BiOCl})_{x}(\mathrm{ZnO})_{1-x}$ composites was calculated from Figure 8 and listed in Table 1 . When the $\mathrm{BiOCl}$ content is at or below $60 \%$, the rate constant $(k)$ increases, and the band gap is reduced. The $k$ achieves the maximum by increasing the $\mathrm{BiOCl}$ content to $75 \%$ and then reversely decreases, albeit with the decreased band gap. It is known that the $k$ represents the photocatalytic degradation activity. Therefore, with the increase of the $k$, the photocatalytic degradation activity is increased. These results demonstrate that the $(\mathrm{BiOCl})_{0.6}(\mathrm{ZnO})_{0.4}$ composites are much more effective, compared with the other cases.

When the $(\mathrm{BiOCl})_{x}(\mathrm{ZnO})_{1-x}$ composites are irradiated by UV light, the excited electrons in the conduction band (CB) of $\mathrm{BiOCl}$ easily jump into the $\mathrm{CB}$ of $\mathrm{ZnO}$, because of their different band energy. Meanwhile, the holes that emerged in the valence band (VB) of $\mathrm{ZnO}$ can migrate to that of $\mathrm{BiOCl}$, which can react with the adsorbed water on the surface of the $\mathrm{BiOCl}$ nanoparticles to form highly reactive hydroxyl radicals $\left(\mathrm{OH}^{*}\right)$. These hydroxyl radicals can oxidize and destroy organic molecules. Meanwhile, the $\mathrm{CB}$ electrons accumulated on the $\mathrm{ZnO}$ surface are removed by dissolved $\mathrm{O}_{2}$ molecules to form highly oxidative species such as $\mathrm{OH}^{*}$ and superoxide radical $\left(\mathrm{O}_{2}^{-\bullet}\right)$, which can degrade organic molecules effectively.

Specifically, the photocatalytic degradation of $\mathrm{RhB}$ is initiated through the formation of electron-hole pairs on the surface of the photocatalyst (Figure 9). The possible mechanism might be described as follows:

$$
\begin{gathered}
\left(\frac{\mathrm{BiOCl}}{\mathrm{ZnO}}\right)+h \nu \longrightarrow \frac{\mathrm{BiOCl}(\oplus)}{\mathrm{ZnO}(\ominus)} \\
\mathrm{ZnO}(\ominus)+\mathrm{O}_{2} \longrightarrow{\mathrm{ZnO}+\mathrm{O}_{2}^{-\bullet}}^{-\bullet} \mathrm{O}_{2}^{-\bullet}+\mathrm{H}_{2} \mathrm{O} \longrightarrow \mathrm{OH}^{-}+\mathrm{HO}_{2} \\
\mathrm{HO}_{2} \cdot+\mathrm{H}_{2} \mathrm{O} \longrightarrow 3 \mathrm{OH}^{\bullet} \\
\mathrm{O}_{2}^{-\bullet}+\mathrm{RhB} \longrightarrow \text { products } \\
\mathrm{OH}^{\bullet}+\mathrm{RhB} \longrightarrow \text { products. }
\end{gathered}
$$

In general, the enhanced photocatalytic activity of $\mathrm{BiOCl} / \mathrm{ZnO}$ heterostructures is attributed to the synergistic photocatalytic effects between $\mathrm{BiOCl}$ and $\mathrm{ZnO}$, its strong absorption in the UV region, and low recombination rate of the electron-hole pairs because of the heterojunction formed between $\mathrm{BiOCl}$ and $\mathrm{ZnO}$. Therefore, the prepared composites can be explored as a promising photocatalyst for the degradation of organic pollutants in dyeing and printing industry. 


\section{Conclusions}

In summary, well-defined nanosheet-assembled nanoflowers of $(\mathrm{BiOCl})_{x}(\mathrm{ZnO})_{1-x}$ with various compositions were synthesized by a simple solvothermal method. The initial content of the $\mathrm{Bi}$ precursor and the mixed solvent with different volume ratios of EG to water are essential for the final size, morphology, and composition of the product. The $(\mathrm{BiOCl})_{0.6}(\mathrm{ZnO})_{0.4}$ composites exhibit improved photocatalytic activity toward the degradation of $\mathrm{RhB}$ under $\mathrm{UV}$ irradiation. The improved photocatalytic activity is attributed to the unique $(\mathrm{BiOCl})_{0.6}(\mathrm{ZnO})_{0.4}$ heterostructures and the synergistic effects between $\mathrm{BiOCl}$ and $\mathrm{ZnO}$, which promote the photoelectrons transfer and thereby inhibit their recombination with holes. The developed strategy about surface structure-property correlation can be further generalized and applied for the design of advanced functional nanomaterials and degradation of organic pollutants in dyeing and printing industry.

\section{Conflict of Interests}

The authors declare that there is no conflict of interests regarding the publication of this paper.

\section{Acknowledgment}

This work was financially supported by the National Natural Science Foundation (no. 21275130).

\section{References}

[1] Q. Xie, J. Li, Q. Tian, and R. Shi, “Template-free synthesis of zinc citrate yolk-shell microspheres and their transformation to $\mathrm{ZnO}$ yolk-shell nanospheres," Journal of Materials Chemistry, vol. 22, no. 27, pp. 13541-13547, 2012.

[2] A.-J. Wang, Q.-C. Liao, J.-J. Feng, P.-P. Zhang, A.-Q. Li, and J.-J. Wang, "Apple pectin-mediated green synthesis of hollow double-caged peanut-like $\mathrm{ZnO}$ hierarchical superstructures and photocatalytic applications," CrystEngComm, vol. 14, no. 1, pp. 256-263, 2012.

[3] Y.-M. Sung, K. Noh, W.-C. Kwak, and T. G. Kim, "Enhanced glucose detection using enzyme-immobilized $\mathrm{ZnO} / \mathrm{ZnS}$ core/sheath nanowires," Sensors and Actuators B: Chemical, vol. 161, no. 1, pp. 453-459, 2012.

[4] J.-J. Feng, Q.-C. Liao, A.-J. Wang, and J.-R. Chen, "Mannite supported hydrothermal synthesis of hollow flower-like $\mathrm{ZnO}$ structures for photocatalytic applications," CrystEngComm, vol. 13, no. 12, pp. 4202-4210, 2011.

[5] P. Zhu, J. Zhang, Z. Wu, and Z. Zhang, "Microwave-assisted synthesis of various $\mathrm{ZnO}$ hierarchical nanostructures: effects of heating parameters of microwave oven," Crystal Growth and Design, vol. 8, no. 9, pp. 3148-3153, 2008.

[6] J.-J. Feng, Z.-Z. Wang, Y.-F. Li, J.-R. Chen, and A.-J. Wang, "Control growth of single crystalline $\mathrm{ZnO}$ nanorod arrays and nanoflowers with enhanced photocatalytic activity," Journal of Nanoparticle Research, vol. 15, pp. 1565-1577, 2013.

[7] L. Ge, X. Jing, J. Wang et al., “Trisodium citrate assisted synthesis of $\mathrm{ZnO}$ hollow spheres via a facile precipitation route and their application as gas sensor," Journal of Materials Chemistry, vol. 21, no. 29, pp. 10750-10754, 2011.

[8] K.-M. Fang, Z.-Z. Wang, M. Zhang, A.-J. Wang, Z.-Y. Meng, and J.-J. Feng, "Gelatin-assisted hydrothermal synthesis of single crystalline zinc oxide nanostars and their photocatalytic properties," Journal of Colloid and Interface Science, vol. 402, pp. 68-74, 2013.

[9] J. R. Bolton, S. J. Strickler, and J. S. Connolly, "Limiting and realizable efficiencies of solar photolysis of water," Nature, vol. 316, no. 6028, pp. 495-500, 1985.

[10] O. Khaselev and J. A. Turner, "A monolithic photovoltaicphotoelectrochemical device for hydrogen production via water splitting," Science, vol. 280, no. 5362, pp. 425-427, 1998.

[11] N. C. S. Selvam, J. J. Vijaya, and L. J. Kennedy, "Effects of morphology and $\mathrm{Zr}$ doping on structural, optical, and photocatalytic properties of ZnO nanostructures," Industrial \& Engineering Chemistry Research, vol. 51, no. 50, pp. 16333-16345, 2012.

[12] H. R. Liu, G. X. Shao, J. F. Zhao et al., "Worm-like Ag/ZnO coreshell heterostructural composites: fabrication, characterization, and photocatalysis," Journal of Physical Chemistry C, vol. 116, no. 30, pp. 16182-16190, 2012.

[13] B. Subash, B. Krishnakumar, M. Swaminathan, and M. Shanthi, "Highly efficient, solar active, and reusable photocatalyst: Zrloaded Ag- $\mathrm{ZnO}$ for reactive red 120 dye degradation with synergistic effect and dye-sensitized mechanism," Langmuir, vol. 29, no. 3, pp. 939-949, 2013.

[14] D. Lin, H. Wu, R. Zhang, and W. Pan, "Enhanced photocatalysis of electrospun $\mathrm{Ag}-\mathrm{ZnO}$ heterostructured nanofibers," Chemistry of Materials, vol. 21, no. 15, pp. 3479-3484, 2009.

[15] X. Zhang, L. Zhang, T. Xie, and D. Wang, "Low-temperature synthesis and high visible-light-induced photocatalytic activity of $\mathrm{BiOI} / \mathrm{TiO}_{2}$ heterostructures," Journal of Physical Chemistry C, vol. 113, no. 17, pp. 7371-7378, 2009.

[16] F.-X. Xiao, "Construction of highly ordered $\mathrm{ZnO}-\mathrm{TiO}_{2}$ nanotube arrays ( $\mathrm{ZnO} / \mathrm{TNTs})$ heterostructure for photocatalytic application," ACS Applied Materials \& Interfaces, vol. 4, no. 12, pp. 7055-7063, 2012.

[17] Z. Zhang, C. Shao, X. Li et al., "Electrospun nanofibers of $\mathrm{ZnO}-\mathrm{SnO}_{2}$ heterojunction with high photocatalytic activity," The Journal of Physical Chemistry C, vol. 114, no. 17, pp. 79207925, 2010.

[18] S. Balachandran and M. Swaminathan, "Facile fabrication of heterostructured $\mathrm{Bi}_{2} \mathrm{O}_{3}-\mathrm{ZnO}$ photocatalyst and its enhanced photocatalytic activity," The Journal of Physical Chemistry C, vol. 116, no. 50, pp. 26306-26312, 2012.

[19] S. Li, K. Yu, Y. Wang et al., " $\mathrm{Cu}_{2} \mathrm{~S} @ Z n O$ hetero-nanostructures: facile synthesis, morphology-evolution and enhanced photocatalysis and field emission properties," CrystEngComm, vol. 15, no. 9, pp. 1753-1761, 2013.

[20] F. Xu, Y. Yuan, H. Han, D. Wu, Z. Gao, and K. Jiang, "Synthesis of $\mathrm{ZnO} / \mathrm{CdS}$ hierarchical heterostructure with enhanced photocatalytic efficiency under nature sunlight," CrystEngComm, vol. 14, no. 10, pp. 3615-3622, 2012.

[21] S. Khanchandani, S. Kundu, A. Patra, and A. K. Ganguli, "Shell thickness dependent photocatalytic properties of $\mathrm{ZnO} / \mathrm{CdS}$ core-shell nanorods," The Journal of Physical Chemistry C, vol. 116, no. 44, pp. 23653-23662, 2012.

[22] T. B. Li, G. Chen, C. Zhou, Z. Y. Shen, R. C. Jin, and J. X. Sun, "New photocatalyst $\mathrm{BiOCl} / \mathrm{BiOI}$ composites with highly enhanced visible light photocatalytic performances," Dalton Transactions, vol. 40, no. 25, pp. 6751-6758, 2011. 
[23] X. Zhang, Z. Ai, F. Jia, and L. Zhang, "Generalized onepot synthesis, characterization, and photocatalytic activity of hierarchical BiOX $(\mathrm{X}=\mathrm{Cl}, \mathrm{Br}, \mathrm{I})$ nanoplate microspheres," The Journal of Physical Chemistry C, vol. 112, no. 3, pp. 747-753, 2008.

[24] K. Zhang, D. Zhang, J. Liu et al., "A novel nanoreactor framework of iodine-incorporated $\mathrm{BiOCl}$ core-shell structure: enhanced light-harvesting system for photocatalysis," CrystEngComm, vol. 14, no. 2, pp. 700-707, 2012.

[25] H. Cheng, B. Huang, X. Qin, X. Zhang, and Y. Dai, "A controlled anion exchange strategy to synthesize $\mathrm{Bi}_{2} \mathrm{~S}_{3}$ nanocrystals/BiOCl hybrid architectures with efficient visible light photoactivity," Chemical Communications, vol. 48, no. 1, pp. 97-99, 2012.

[26] S. Weng, B. Chen, L. Xie, Z. Zheng, and P. Liu, "Facile in situ synthesis of a $\mathrm{Bi} / \mathrm{BiOCl}$ nanocomposite with high photocatalytic activity," Journal of Materials Chemistry A, vol. 1, no. 9, pp. 30683075, 2013.

[27] J.-M. Song, C.-J. Mao, H.-L. Niu, Y.-H. Shen, and S.-Y. Zhang, "Hierarchical structured bismuth oxychlorides: Self-assembly from nanoplates to nanoflowers via a solvothermal route and their photocatalytic properties," CrystEngComm, vol. 12, no. 11, pp. 3875-3881, 2010.

[28] L.-P. Zhu, G.-H. Liao, N.-C. Bing, L.-L. Wang, Y. Yang, and H.-Y. Xie, "Self-assembled 3D BiOCl hierarchitectures: tunable synthesis and characterization," CrystEngComm, vol. 12, no. 11, pp. 3791-3796, 2010.

[29] M. Ge, Y. Li, L. Liu, Z. Zhou, and W. Chen, " $\mathrm{Bi}_{2} \mathrm{O}_{3}-\mathrm{Bi}_{2} \mathrm{WO}_{6}$ composite microspheres: hydrothermal synthesis and photocatalytic performances," The Journal of Physical Chemistry C, vol. 115 , no. 13, pp. 5220-5225, 2011.

[30] A.-J. Wang, Q.-C. Liao, J.-J. Feng, P.-P. Zhang, Z.-M. Zhang, and J.-R. Chen, "D-Penicillamine-assisted self-assembly of hierarchical PbS microstars with octa-symmetric-dendritic arms," Crystal Growth \& Design, vol. 12, pp. 832-841, 2012.

[31] Z. Wang, S.-W. Cao, S. C. J. Loo, and C. Xue, "Nanoparticle heterojunctions in $\mathrm{ZnS}-\mathrm{ZnO}$ hybrid nanowires for visible-lightdriven photocatalytic hydrogen generation," CrystEngComm, vol. 15 , no. 28, pp. 5688-5693, 2013.

[32] S. Zhang, Y. Du, H. Li et al., "Evidence of matrix lattice distortion in $\mathrm{Zn}_{1-x} \mathrm{Co}_{x} \mathrm{O}$ nanocrystals," The Journal of Physical Chemistry C, vol. 113, no. 11, pp. 4263-4269, 2009. 

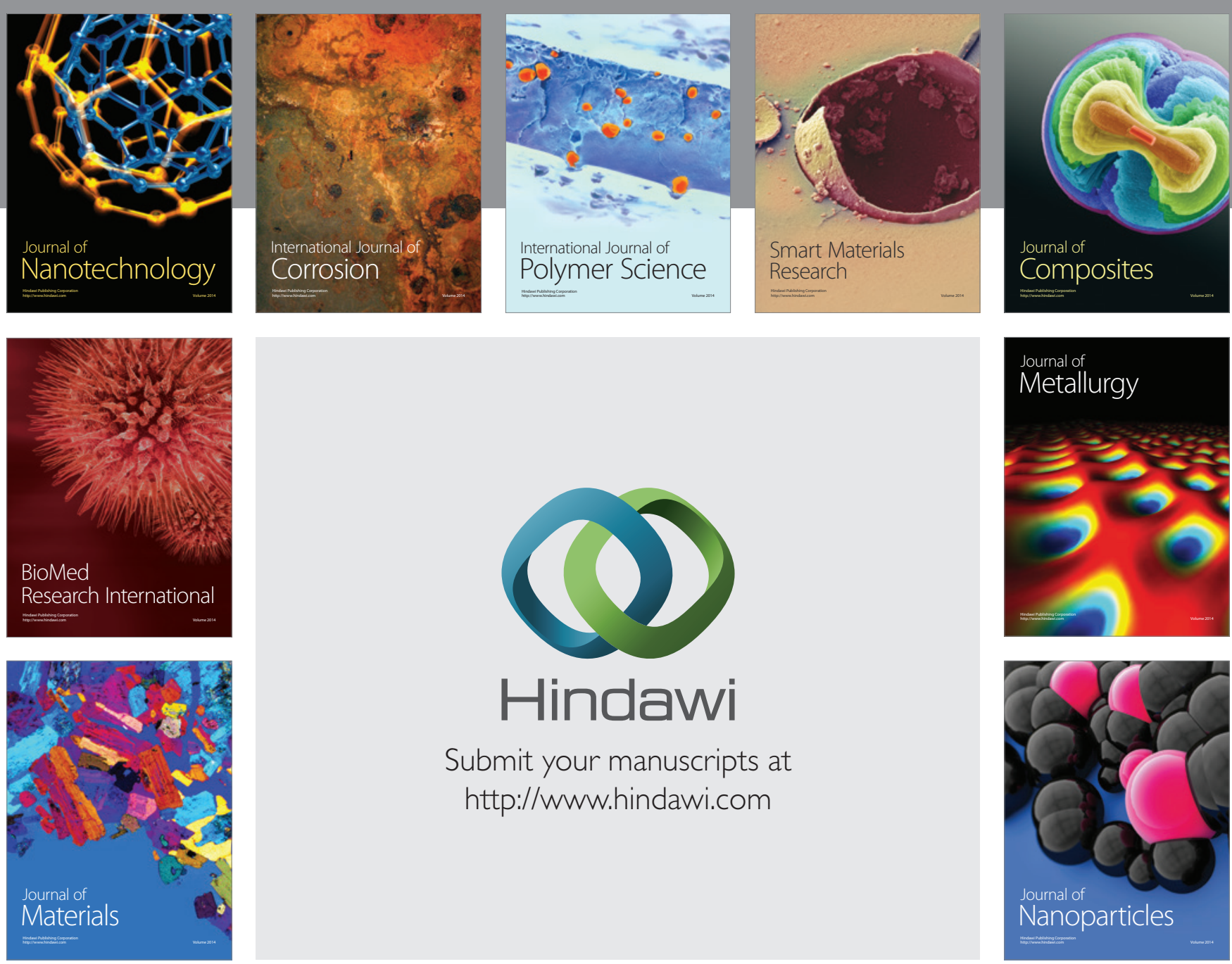

Submit your manuscripts at http://www.hindawi.com
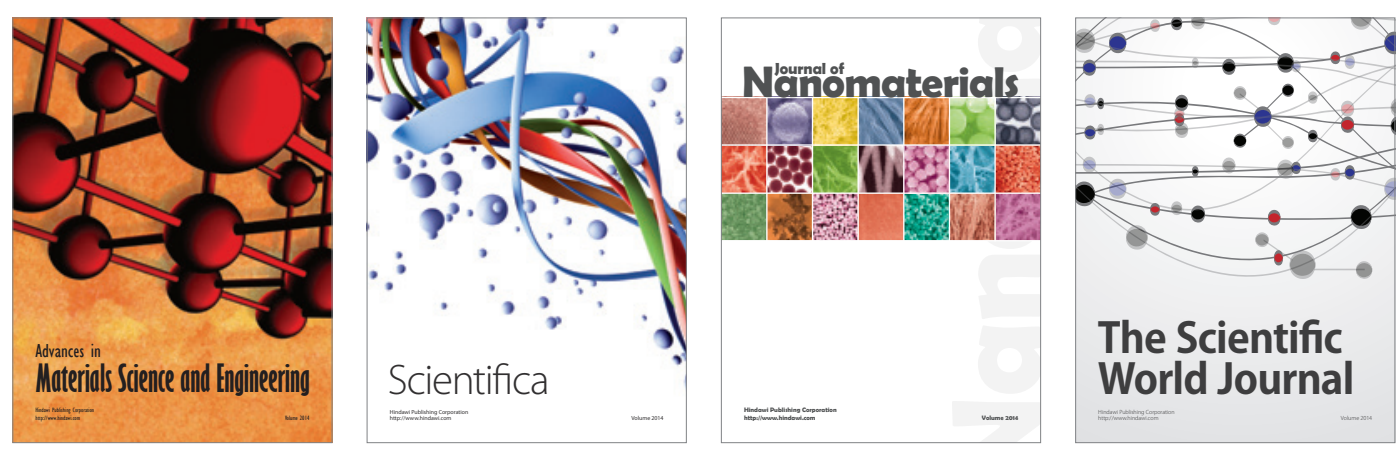

\section{The Scientific World Journal}
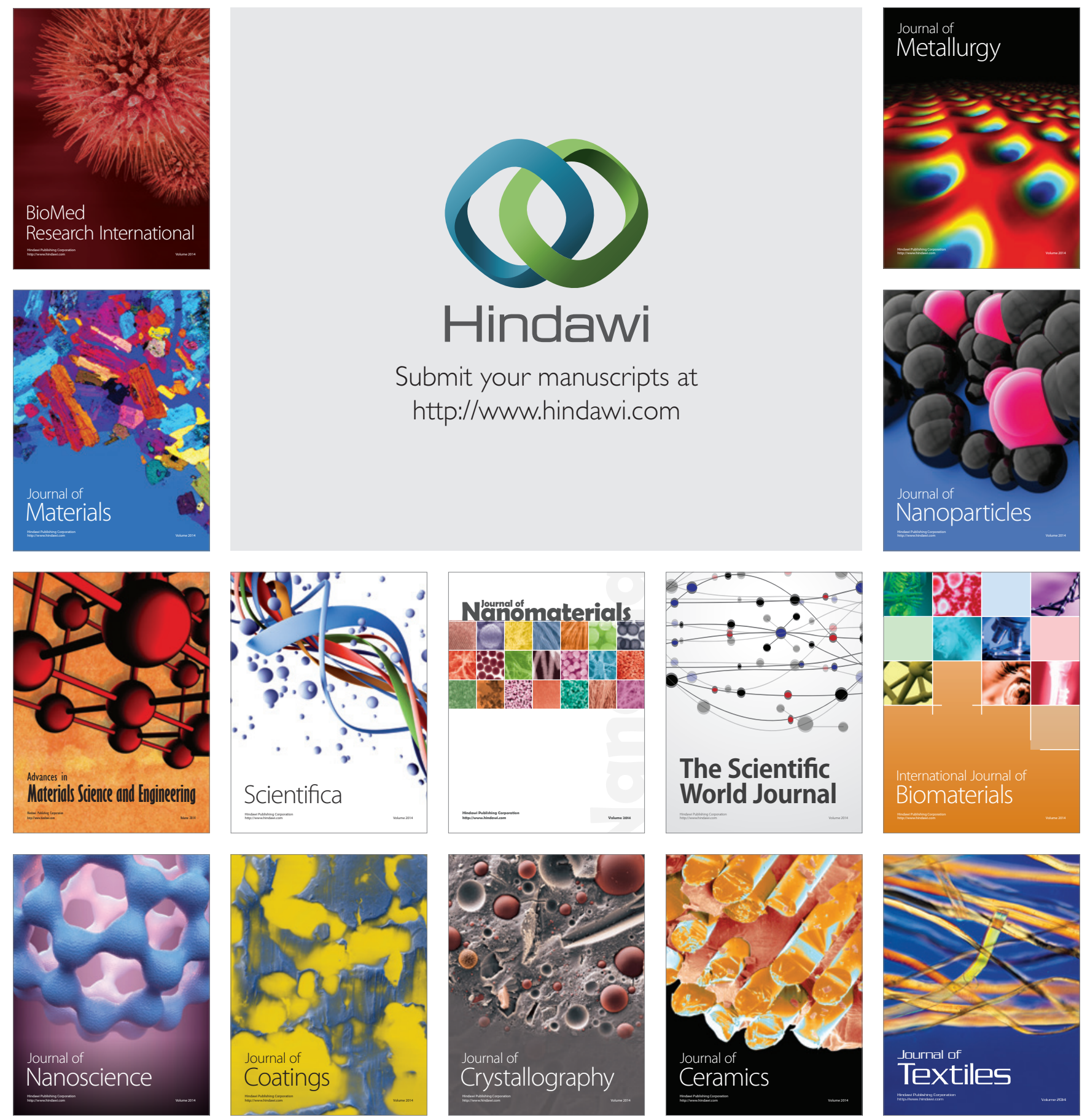